\title{
Effects of gentamicin on spontaneous and agonist-induced in vitro contractions of isolated myometrial tissue from pregnant cows
}

\author{
MURAT YUKSEL, HALIS OCAL*, AHMET AYAR** \\ Department of Obstetrics and Gynaecology, Faculty of Veterinary Medicine, \\ Sivas Cumhuriyet University, TR-58140 Sivas, Turkey \\ *Department of Obstetrics and Gynaecology, Faculty of Veterinary Medicine, Firat University, TR-23000 Elazig, Turkey \\ **Department of Physiology, Faculty of Medicine, Karadeniz Technical University, TR-61080 Trabzon, Turkey
}

\section{Yuksel M., Ocal H., Ayar A.}

\section{Effects of gentamicin on spontaneous and agonist-induced in vitro contractions of isolated myometrial tissue from pregnant cows}

\section{Summary}

The aim of the present study is to examine the effects of gentamicin sulphate on spontaneous, oxytocin and PGF $_{2 \alpha}$ induced in vitro contractions of myometrium isolated from pregnant cows.

Myometrial strips were obtained from healthy pregnant cows and suspended in a covered organ bath filled with Krebs' solution at $37^{\circ} \mathrm{C}(\mathrm{pH} 7.4)$ continuously bubbled with $95 \%$ oxygen and $5 \%$ carbon dioxide: isometric contractions were recorded using an isometric force displacement transducer. After the stabilization of spontaneous contractile activity during a 90-minute equilibration period, contractions were recorded for 20 minutes (control). Gentamicin sulphate was then added to the tissue bath cumulatively and the responses were recorded every 20-minutes for each consecutive dose of gentamicin. In agonist-induced contractions, oxytocin or PGF $_{2 \alpha}$ was added to the tissue bath at the end of the equilibration period and the same protocol was followed to investigate the effects gentamicin on these agonist-induced contractions.

Gentamicin decreased the frequency and inhibited the amplitude of the spontaneous contractions in a dose dependent manner $(p<0.05)$. The mean frequency and amplitude of oxytocin-induced contractions was significantly inhibited by the application of gentamicin $(p<0.05)$. Gentamicin also inhibited the contractions induced by $\mathrm{PGF}_{2 \alpha}$ in a dose dependent manner $(\mathrm{p}<0.05)$. This study showed gentamicin inhibited, depending on the dosage, oxytocin and $\mathbf{P G F}_{2 \alpha}$ induced contractions of myometrium isolated from pregnant cows. Upon clinically examining the findings obtained by the study, gentamicin can be used as antibacterial in septic abort and chorioamniotis in order to prevent premature birth, abortion and early uterus contractions. Further studies are necessary to test whether the same effect will take place in vivo and to examine the effects of longterm use of gentamicin on offsprings.

Keywords: gentamicin, bovine, myometrium, contractility, oxytocin, $\mathrm{PGF}_{2 \alpha}$

In mammalians the uterus is at rest during pregnancy until near birth. Local, maternal, mechanical or fetal stimuli cause the myometrium, which is at rest, to contract during birth. The frequency and amplitude of these contractions are high until the birth is completed (38). The molecular mechanisms including myometrial contractions and birth control in species such as humans, goats, and cows have been explained comprehensively in previous studies $(15,38)$. The control of myometrial contractions is critical not only for the management and understanding of regular birth, but also for early response to and the understanding of post- partum uterus involution. The cattle myometrium has the ability to contract spontaneously, as it consists of smooth muscles (10-12). Known as myogenic activity, this contraction is basically managed by the hormonal (9) and neural systems $(13,36)$.

There are many studies on the effects of antibiotics on the contractions of smooth muscles, including the uterus $(2,8,31)$. It has been reported that rifaximin stimulates uterus contractions in nonpregnant cows (32) and that ceftiofur has an additive effect on the strength of contractile activity of the myometrium, as shown in an in vitro study on nonpregnant heifers 
and cows (31). In another study, it was reported that amoxicillin inhibits uterus contractions, enrofloxacin increases contraction and rifaximin increases contraction in the follicular phase and causes relaxation in the luteal phase (29). It has been determined that erythromycin inhibits oxytocin and carbacol-induced uterus contractions in pregnant rats (8), and that it also inhibits $\mathrm{PGF}_{2 \alpha}$-induced uterus contractions in nonpregnant rats (2). It has also been shown that clarithromycin inhibits human uterus contractions (1), and that pre-treatment with fosfomycin and amoxicillin improves the oxytocin sensitivity of the pregnant rat uterus, while doxycycline does not affect this mechanism (3).

Gentamicin, which belongs to the aminoglycoside antibiotic group, has bactericidal effects, and it is commonly used in the treatment of serious infections induced by gram negative aerobic bacteria, including Pseudomonas aeruginosa, several gram positive bacteria, as well as Mycoplasma and Staphylococcus species $(4,19)$. Gentamicin has autotoxic effects, but its main toxic effect is nephrotoxicosis. Nowadays, high dosage and once-daily dosing are recommended in most treatment protocols in order to improve antimicrobial activity of gentamicin and to reduce its nephrotoxic effect to the minimum. If bacteriological examination and antibiogram results show that an aminoglycoside is required, gentamicin should be preferred first as there is more knowledge on its usage during pregnancy (4). It has been reported that in pregnant mares in which placentitis have developed, gentamicin accumulates in adequate amounts in amniotic fluid when used alone or with other antibiotics (17), and that the treatment is successful, therefore, early birth is prevented, allowing healthier births to take place (16).

It has been reported that the aminoglycoside group of antibiotics, including gentamicin, inhibit spontaneous rat myometrium contractions, but do not affect contractions induced by oxytocin and $\mathrm{PGF}_{2 \alpha}(25,26)$. It was also shown in an in vitro study that gentamicin inhibits spontaneous and agonist-induced contractions in nonpregnant cows (22). In another in vitro study, it was shown that it inhibits KCI-induced contractions in both pregnant and nonpregnant cows (23).

Although there are various studies on the effects of antibiotics, including gentamicin, on different types of uterus contractions, no study has been carried out on the effects of gentamicin on spontaneous and agonistinduced contractions of pregnant cow myometrium.

The purpose of this study was to examine the effects of gentamicin sulphate on spontaneous, oxytocin and $\mathrm{PGF}_{2 \alpha}$ induced in vitro contractions of myometrium isolated from pregnant cows.

\section{Material and methods}

Myometrial strips used in this study were obtained from healthy cows slaughtered at the local abattoir. Immediately after the slaughter, uterus and ovaries were visually exam- ined to determine pathologic conditions of the genital tract, and myometrial samples were dissected only from cows that were diagnosed to have a healthy genital tract and found to be pregnant for at least six months.

The time between the slaughter of cows and the collection of uterus and ovaries was about $20 \mathrm{~min}$. A single $25 \times 5 \mathrm{~mm}$ full-thickness uterus sample from the larger horn near the uterine body was removed and rapidly transferred (the average transportation time was about $15 \mathrm{~min}$ ) from the abattoir to the laboratory, placed in a test tube containing Krebs' solution. Experiments started within 30 to 120 minutes of the removal of the tissue samples. The tissue samples remained viable in this condition for the first 6 to 12 hours of the experiment, as judged by the stability of the amplitude of spontaneous, oxytocin and $\mathrm{PGF}_{2 \alpha}$-induced contractions.

Small strips (15 mm lengths and $5 \mathrm{~mm}$ width, relaxed) consisting of the longitudinal fiber layer of the myometrium were cut from the uterus samples. Only one strip from each animal was used for the same experiment protocol. These strips were immediately placed in a covered organ bath containing $20 \mathrm{ml}$ of Krebs' solution $(\mathrm{NaCl} 6.9 \mathrm{~g}$; $\mathrm{KCl}$ $0.35 \mathrm{~g} ; \mathrm{MgCl}_{2} \times 6 \mathrm{H}_{2} \mathrm{O} 0.24 \mathrm{~g} ; \mathrm{NaHCO}_{3} 1.99 \mathrm{~g} ; \mathrm{KH}_{2} \mathrm{PO}_{4}$ $0.16 \mathrm{~g}$; Dextrose $0.99 \mathrm{~g}$ and $\mathrm{CaCl}_{2} \times 2 \mathrm{H}_{2} \mathrm{O} 0.368 \mathrm{~g}$ per liter) at $37^{\circ} \mathrm{C}$ continuously bubbled with $95 \%$ oxygen and $5 \%$ carbon dioxide. To measure isometric tension, the distal end of the muscle strips was tied to a fixed glass hook and the proximal end to an isometric force displacement transducer (Harvard Apparatus Limited, Kent, England). The contractile activities of strips were recorded using a Harvard Universal Oscillograph (Harvard Apparatus Limited, Kent, England).

The myometrial strips were initially placed under $2.0 \mathrm{~g}$ tension and they were left for equilibration for 90-min before the start of each experiment. In our previous studies on cow myometrium, $2.0 \mathrm{~g}$ of tension was determined to be optimal $(22,23)$. Most of the strips developed spontaneous contractions within 30 to 90 minute and the strips with no regular spontaneous activity in this equilibration period were removed. Eight, 10 and 9 myometrial strips were used in the analysis of spontaneous, oxytocin-induced and $\mathrm{PGF}_{2 \alpha}$-induced contractions respectively.

The following experiment protocol was performed after the stabilization of spontaneous contractile activity during the 90-minute equilibration period. The contractions were recorded for 20 minutes in order to monitor their status. Cumulative doses of gentamicin sulphate were then added over a concentration range of $150 \mu \mathrm{M}-300 \mu \mathrm{M}$ for spontaneous contraction and $300 \mu \mathrm{M}-600 \mu \mathrm{M}$ for oxytocin and $\mathrm{PGF}_{2 \alpha}$-induced contractions at $20 \mathrm{~min}$ intervals, respectively. The responses were recorded for another 20 minutes. Thus, each gentamicin concentration had its own control phase (22). In agonist-induced contractions, oxytocin ( $2.5 \mathrm{mIU} / \mathrm{ml}$ bath fluid) or $\mathrm{PGF}_{2 \alpha}(1 \mu \mathrm{M})$ was added to the tissue bath at the end of the equilibration period and the same protocol was performed in order to investigate the effects gentamicin on these agonist-induced contractions. These amounts of agonists were chosen as they were known to elicit a response in cow myometrium (15). 
The effects of gentamicin on the amplitude (reported in grams) and the frequency of contractions (number of contractions/20 minute-period) were analyzed for every $20 \mathrm{~min}$. The mean amplitude and frequency of contractions were compared.

The drug used in the present study was gentamicin sulphate (Gentasol, Eczacibasi, Istanbul, Turkey), $\mathrm{PGF}_{2 \alpha}$ (Sigma, Deisenhofen, Germany) and oxytocin (Synpitan iv, $5 \mathrm{IU} / \mathrm{ml}$, Deva, Istanbul, Turkey). All the chemicals used in the preparation of the Krebs' solution were obtained from Sigma (Sigma, Deisenhofen, Germany) and medical grade chemicals.

All values are expressed as means \pm SEM. Statistical analyses were calculated by SPSS release 22 for Windows (SPSS Inc, Illanos, CA). Wilcoxon signed rank test was used for the calculation of amplitude and frequency differences between control and drug periods. Statistical significance was assumed as $5 \%$.

\section{Results and discussion}

The tissue samples were allowed to equilibrate under $2 \mathrm{~g}$ of resting tension, and spontaneous contractions were established in 27 out of the 35 tissue samples studied; the remaining 5 strips without spontaneous contractions in the equilibration period and the 3 strips with irregular spontaneous contractions were excluded from the study.

Gentamicin decreased the frequency (number/ 20 minute period) and inhibited the amplitude of the spontaneous contractions in a dose dependent manner (Fig. 1). The mean frequency of spontaneous contractions was $10.59 \pm 1.02(\mathrm{n}=8)$ under control conditions, which were significantly inhibited to $7.17 \pm 1.19(\mathrm{n}=8, \mathrm{p}<0.05)$ and $3.5 \pm 1.26(\mathrm{n}=8$, $\mathrm{p}<0.05$ ) after the incremental application of 150 and $300 \mu \mathrm{M}$ gentamicin, respectively (Fig. 1). Gentamicin also inhibited the amplitude of spontaneous contractions, but not as strongly as it inhibited the frequency. The mean peak amplitude of contractions was $3.3 \pm 0.23 \mathrm{~g}(\mathrm{n}=8)$ under control conditions, and 2.58 $\pm 0.29 \mathrm{~g}(\mathrm{n}=8, \mathrm{p}>0.05)$ and $1.28 \pm 0.43 \mathrm{~g}(\mathrm{n}=8$, $\mathrm{p}<0.05$ ) after the incremental application of 150 and $300 \mu \mathrm{M}$ gentamicin, respectively (Fig. 2).

The mean frequency (number/20 minute period) of oxytocin-induced ( $2.5 \mathrm{mIU})$ contractions was significantly inhibited from the control values of $18.4 \pm 2.05$ $(\mathrm{n}=10)$ to $10 \pm 1.92(\mathrm{n}=10, \mathrm{p}<0.05)$ and $4.0 \pm 1.41$ $(\mathrm{n}=10, \mathrm{p}<0.05)$ after the application of 300 and 600 $\mu \mathrm{M}$ gentamicin, respectively (Fig. 1). Gentamicin also inhibited the amplitude of oxytocin-induced contractions. The amplitude of oxytocin-induced contractions was $3.30 \pm 0.20 \mathrm{~g}(\mathrm{n}=10)$ under control conditions and $2.71 \pm 0.15 \mathrm{~g}(\mathrm{n}=10, \mathrm{p}<0.05)$ and $1.50 \pm 0.39 \mathrm{~g}$ $(\mathrm{n}=10, \mathrm{p}<0.05)$ after application of 300 and $600 \mu \mathrm{M}$ gentamicin, respectively (Fig. 2).

Gentamicin also inhibited the contractions induced by $\operatorname{PGF}_{2 \alpha}(1 \mu \mathrm{M})$ in a dose dependent manner. The frequency (number/20 minute period) of $\mathrm{PGF}_{2 \alpha}$-induced

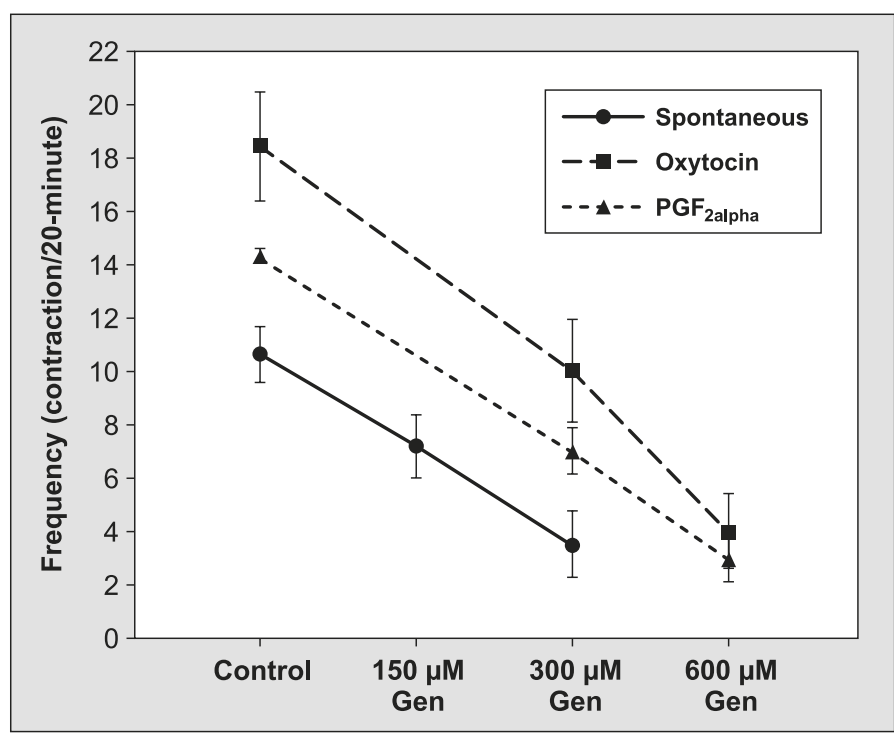

Fig. 1. Effects of gentamicin sulphate (Gen) on mean frequency of spontaneous, oxytocin and $\mathrm{PGF}_{2 \text { alpha }}$-induced contraction

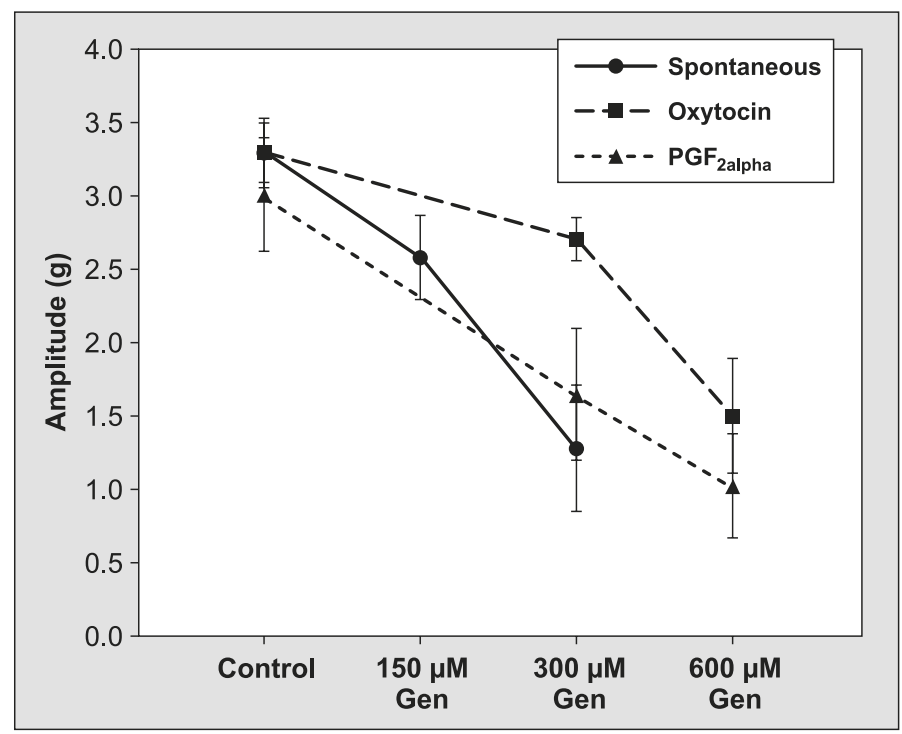

Fig. 2. Effects of gentamicin sulphate (Gen) on mean amplitude of spontaneous, oxytocin and $\mathrm{PGF}_{2 \text { alpha }}$-induced contraction

contractions was $14.3 \pm 0.3(\mathrm{n}=9)$ under control conditions and, $7.0 \pm 0.87(\mathrm{n}=9, \mathrm{p}<0.05)$ and $3.0 \pm 0.9$ $(\mathrm{n}=9, \mathrm{p}<0.05)$ after the application of 300 and $600 \mu \mathrm{M}$ gentamicin, respectively (Fig. 1). Application of $300 \mu \mathrm{M}$ and $600 \mu \mathrm{M}$ gentamicin significantly inhibited the mean amplitude of $\mathrm{PGF}_{2 \alpha}$-induced contractions from control values of $3.01 \pm 0.39 \mathrm{~g}(\mathrm{n}=9)$ to 1.65 $\pm 0.45 \mathrm{~g}(\mathrm{n}=9, \mathrm{p}<0.05)$, and $1.02 \pm 0.35 \mathrm{~g}(\mathrm{n}=9$, $\mathrm{p}<0.05$ ), respectively (Fig. 2).

The result of this in vitro study has shown that gentamicin sulphate has inhibitory effects on both spontaneous and induced contractions of the myometrium tissue obtained from pregnant cows.

Previous studies have shown that various antibiotics not included in the aminoglycoside group, such as clarythromicin (1), erythromicin (37), rifaximin (28, 29,32 ), fosfomycin, amoxicillin and doxycyline (3), ceftiofur (31), enrofloxacin $(24,28,29)$ and amoxicillin 
$(28,29)$, have different effects on uterus contractions. It has been reported that some antibiotics stimulate $(28,29,31,32)$ while some other suppress myometrial contractions $(1,24,37)$. Previous in vitro studies have shown that gentamicin inhibits spontaneous contractions of the isolated uterus in nonpregnant rats (25) and cows (22). However, it has been established that aminoglycoside group antibiotics, including gentamicin, are not effective on oxytocin and prostaglandine induced contractions in the rat uterus (26), but they act as an inhibitory on KCI-induced contractions in pregnant and nonpregnant cow myometrium (23). In other studies, it has been determined that gentamicin act as a suppressive on oxytocin-induced contractions in cat myometrium (33) and in nonpregnant cattle myometrium (34); however, in a different study by the same researchers on rat uterus (35) it was found that gentamicin has inhibitory effects on both spontaneous and oxytocin-induced contractions.

In our study, 27 of 35 muscle samples showed regular spontaneous contractions, and as has been the case in previous studies $(7,20,22,27,34)$ oxytocin and $\mathrm{PGF}_{2 \alpha}$ increased the spontaneous contractions of myometrium tissue obtained from pregnant cows. Unlike the results of Paradelis et al. (26), gentamicin also inhibited, depending on dosage, oxytocin and $\mathrm{PGF}_{2 \alpha}$ induced contractions in uterus isolated from pregnant cows. Difference in species can be the cause of this variance in the effect of gentamicin. Nonetheless, the dosage of gentamicin used in this study was higher than that which was used on isolated rat uterus. Our findings obtained were similar to the results obtained by Ocal et al. (23) and Servi and Kara (33-35).

Although the current study did not examine the inhibition mechanism of gentamicin sulfate on contractions in cow myometrium, it was reported that when the inhibitory effect of gentamicin is exerted calcium (data not shown) added to the organ bath have significantly enabled the contractions to repeat, as in previous studies $(25,26)$. This suggests a possible intervention in the inhibitory effect of gentamicin sulfate on its inhibition of membrane calcium channels during myometrial contractions. This finding can be considered as an indication for that the inhibitory effect of gentamicin sulfate on the contractions of isolated pregnant cow myometrium takes place without damaging tissue viability or contraction mechanism.

Vesce et al. (37) showed in their studies that gentamicin inhibited amniotic PGE oscillation induced by both basal and arachidonic and oxytocin. In the in vitro study conducted by Escoubet et al. (6), it was shown that gentamicin apparently and alternately inhibited the synthesis of prostaglandins produced by the vascular structures of inner ear. In light of the mentioned information, it can be suggested that the inhibition of local prostaglandin synthesis is at least partially responsible for the inhibition stimulated by gentamicin sulfate on isolated cow myometrial tissue.
In the studies on pony mares, it was reported that when a bacterial infection causes the formation of a disease, premature birth occurs not as a result of fetal inflammation but as a result of secondary chorion inflammation $(14,18)$. These inflammatory processes are a result of the production of prostaglandins $\left(\mathrm{PGE}_{2}\right.$ and $\left.\mathrm{PGF}_{2 \alpha}\right)$ and the stimulation of myometrial contractions, leading to premature birth $(5,16,30)$. In the study by Murchie et al. (21), it has been established that the allantoic fluid concentration of gentamicin is at adequate levels so as to be effective against $E$. coli or $K$. pneumoniae. In another study, it has been reported that the use of gentamicin with antiinflammatories on mares with placentitis can contribute positively to the continuation of pregnancy (16). It has also been suggested that urinary organ infections, including incurable pyelonephritis in humans, can cause serious issues, such as premature birth, low birth weight, and sepsis (39).

Upon clinically examining the findings obtained by the study and the mentioned information, gentamicin can be used as an antibacterial in septic abort, chorioamniotis, pyelonephritis, and septic shock cases, in order to prevent premature birth, abortion and early uterus contractions (25). In conclusion, it has been determined that gentamicin inhibits both spontaneous and oxytocin and $\mathrm{PGF}_{2 \alpha}$ induced contractions in isolated cow uterus. Further studies are necessary to test whether the same effect will take place in vivo and to examine the effects of long-term use of gentamicin on offspring.

\section{References}

1. Celik H., Ayar A.: Clarithromycin inhibits myometrial contractions in isolated human myometrium independent of stimulus. Physiol. Res. 2002, 51, 239-245.

2. Celik H., Ayar A., Tug N., Baltaci A. K.: Erythromycin inhibits prostaglandin F2alpha-induced contractions of myometrium isolated from non-pregnant rats. BJOG 2002, 109, 1036-1040.

3. Csányi A., Hajagos-Tóth J., Kothencz A., Gaspar R., Ducza E.: Effects of different antibiotics on the uterine contraction and the expression of aquaporin 5 in term pregnant rat. Reprod. Toxicol. 2018, 81, 64-70.

4. Dowling P. M.: Aminoglycosides and aminocyclitols, [in:] Giguère S., Prescott J. F., Dowling P. M. (eds.): Antimicrobial therapy in veterinary medicine. $5^{\text {th }}$ ed., John Wiley \& Sons Inc., Iowa 2013, p. 233-256.

5.Dudley D. J., Trautman M. S.: Infection, inflammation, and contractions - the role of cytokines in the pathophysiology of preterm labor. Semin. Reprod. Med. 1994, 12, 263-272.

6. Escoubet B., Amsallem P., Ferrary E., Tran Ba Huy P.: Prostaglandin synthesis by the cochlea of the guinea pig. Influence of aspirin, gentamicin, and acoustic stimulation. Prostaglandins 1985, 29, 589-599.

7. Górriz-Martína L., Ulbrich S. E., Schmicke M., Hirsbrunner G., Keller C., Yücesoy N., Pfarrer C., Bollwein H., Heppelmann M.: The myometrial contractility during late pregnancy in dairy cows, in vitro. Anim. Reprod. Sci. 2017, 181, 130-140.

8. Granovsky-Grisaru S., Ilan D., Grisaru D., Lavie O., Aboulafia I., Diamant Y. Z., Hanani M.: Effects of erythromycin on contractility of isolated myometrium from pregnant rats. Am. J. Obstet. Gynecol. 1998, 178, 171-174.

9. Hertelendy F., Zakar T.: Prostaglandins, the myometrium and the cervix. Prostaglandins Leukot. Essent. Fatty Acids 2004, 70, 207-222.

10. Hirsbrunner G., Eicher R., Küpfer U., Burkhardt H., Steiner A.: Effect of different doses of prostaglandin E2 on intrauterine pressure and uterine motility during diestrus in experimental cows. Theriogenology 2000, 54, 291-303.

11. Hirsbrunner G., Knutti B., Liu I., Kupfer U., Scholtysik G., Steiner A.: An in vitro study on spontaneous myometrial contractility in the cow during estrus and diestrus. Anim. Reprod. Sci. 2002, 70, 171-180. 
12. Kaufmann C., Keller C., Oevermann A., Steiner A., Hirsbrunner G.: Spontaneous contractility of bovine myometrium in vitro depending on topography and cycle phase. Theriogenology 2008, 70, 880-886.

13. Kyozuka M., Crankshaw D. J., Crankshaw J., Berezin I., Kwan C. Y., Daniel E. E.: Alpha-2 adrenoceptors on nerves and muscles of rat uterus. J. Pharmacol. Exp. Ther. 1988, 244, 1128-1138.

14. Leblanc M. M., Giguere S., Brauer K., Paccamonti D. L., Horohov D. W., Lester G. D., O'Donnel L. J., Sheerin B. R., Pablo L., Rodgerson D. H.: Premature delivery in ascending placentitis is associated with increased expression of placental cytokines and allantoic fluid prostaglandins E-2 and F-2 alpha. Theriogenology 2002, 58, 841-844.

15. Lye S. J., Ou C. W., Teoh T. G., Erb G., Stevens Y., Casper R., Patel F. A., Challis J. R. G.: The molecular basis of labour and tocolysis. Fetal. Matern. Med. Rev. 1998, 10, 121-136.

16. Macpherson M. L.: Treatment strategies for mares with placentitis. Theriogenology 2005, 64, 528-534.

17. Macpherson M. L., Bailey C. S.: Treating the mare with placentitis: A clinical approach. J. Equine Vet. Sci. 2008, 28, 703-708.

18. Mays M. B. C., Leblanc M. M., Paccamonti D.: Route of fetal infection in a model of ascending placentitis. Theriogenology 2002, 58, 791-792.

19. McEwen S. A., Fedorka-Cra P. J.: Antimicrobial use and resistance in animals Clin. Infect. Dis. 2002, 34, 93-106.

20. Morrison J. J., Crosby D. A., Crankshaw D. J.: In vitro contractile effects of agents used in the clinical management of postpartum haemorrhage. Eur. J. Pharmacol. 2016, 789, 328-333.

21. Murchie T. A., Macpherson M. L., Leblanc M. M., Luznar S. L., Vickroy T. W. A microdialysis model to detect drugs in the allantoic fluid of pregnant pony mares. American Association of Equine Practitioners (AAEP) Proc. 49, 2003 , 118-119.

22. Ocal H., Yuksel M., Ayar A.: Effects of gentamicin sulfate on the contractility of myometrium isolated from non-pregnant cows. Anim. Reprod. Sci. 2004, 84, 269-277

23. Ocal H., Yuksel M., Ayar A.: Gentamycin inhibition of $\mathrm{KCl}$-induced contractions of myometrium isolated from non-pregnant and pregnant cows. Vet. Med. 2004, 49, 401-405.

24. Paksoy Z., Kurt A. H., Ergün Y.: The effect of enrofloxacin on myometrial contractility in bitches. Harran Univ. Vet. Fak. Derg. 2016, 5, 152-155.

25. Paradelis A. G., Tarlatzis B. C., Triantaphyllidis C. J., El-Messidi M. M., Papaloucas $A$. C.: Effect of aminoglycoside antibiotics on the contractility of the uterus. Methods Find. Exp. Clin. Pharmacol. 1982a, 4, 337-341.

26. Paradelis A. G., Triantaphyllidis C., Tarlatzis B. C., Tsouras J. S., El-Messidi M. M., Papaloucas A. C.: Interaction of aminoglycoside antibiotics with oxytocin and prostaglandin E2 on uterine contractility. Methods Find. Exp. Clin. Pharmacol. 1982b, 4, 343-345.
27. Patil R. K., Sinha S. N., Einarsson S., Settergren I.: The effect of prostaglandin F2 alpha and oxytocin on bovine myometrium in vitro. Nord. Vet. Med. 1980, 32, 474-479.

28. Piccinno M., Rizzo A., Cariello G., Staffieri F., Sciorsci R. L.: Oxytocin plus antibiotics: A synergism of potentiation to enhance bovine uterine contractility. Theriogenology 2016, 86, 1203-1211.

29. Piccinno M., Rizzo A., Maselli M. A., Derosa M., Sciorsci R. L.: Modulatory effect of three antibiotics on uterus bovine contractility in vitro and likely therapeutic approaches in reproduction. Theriogenology 2014, 82, 1287-1295.

30. Pollard J. K., Mitchell M. D.: Intrauterine infection and the effects of inflammatory mediators on prostaglandin production by myometrial cells from pregnant women. Am. J. Obstet. Gynecol. 1996, 174, 682-686.

31. Saat N., Ocal H.: Effects of Ceftiofur on conctractions of uterine isolated from non-pregnant cows. F.U. Sag. Bil. Vet. Derg. 2015, 29, 31-36.

32. Sciorsci R. L., Piccinno M., Rizzo A.: Contractile effect of rifaximin on bovine uterus in the presence of steroid hormone antagonists. Theriogenology 2018, 110, 74-78.

33. Servi K., Kara H.: Effects of different doses of gentamicin on cat myometrium in vitro. F.U. Sag. Bil. Vet. Derg. 2001a, 15, 381-386.

34. Servi K., Kara H.: Effects of different doses of gentamicin on cow myometrium contractile with oxytocine-induced in vitro. F.U. Sag. Bil. Vet. Derg. 2001b, 15, 189-194

35. Servi K., Kara H.: Investigation of the effects of different doses gentamicin and erythromycin on spontaneous and oxytocin-induced myometrium contractiles in rats in vitro. F.U. Sag. Bil. Vet. Derg. 2001c, 15, 199-206.

36. Taneike T., Bando S., Takasaki K., Okumura M., Sato H., Teraoka H., Kitazawa T., Ohga A.: Muscle layer and regional differences in autonomic innervation and responsiveness to transmitter agents in swine myometrium. J. Auton. Pharmacol. 1994, 14, 213-227.

37. Vesce F., Pavan B., Buzzi M., Pareschi M. C., Bianciotto A., Iorizzo G., Biondi $C$.: Effect of different classes of antibiotics on amniotic prostaglandin E release. Prostaglandins Other Lipid Mediat. 1999, 57, 207-218.

38. Wray S.: Uterine contraction and physiological mechanisms of modulation. Am. J. Physiol. 1993, 264, 1-18.

39. Zefirova J. T., Zefirova T. P., Ziganshina L. E., Ziganshin A. U.: Effects of chronic specific urogenital infections on contractility of the human isolated pregnant myometrium. Auton. Neurosci. 2002, 99, 58-61.

Corresponding author: Murat YUKSEL, DVM, PhD, Department of Obstetrics and Gynaecology, Faculty of Veterinary Medicine, Sivas Cumhuriyet University, TR-58140 Sivas, Turkey; e-mail: muyuksel@yahoo.com 